\title{
Papel dos avós: apoio oferecido aos netos antes e após situações de separação/divórcio dos pais
}

\author{
Mayeve Rochane Gerônimo Leite Araújo \\ Universidade Estadual da Paraíba \\ Cristina Maria de Souza Brito Dias \\ Universidade Católica de Pernambuco
}

\begin{abstract}
Resumo
A presente pesquisa teve como objetivo averiguar os tipos de apoio oferecidos pelos avós aos netos antes e após situações de separação/divórcio dos pais, bem como a existência ou não de alterações nas formas de apoio. Foram considerados dois tipos de apoio: o emocional e o instrumental, sob a influência das seguintes variáveis: distância geográfica, custódia parental, vinculação materna ou paterna, idade, situação empregatícia e estado civil dos avós. Participaram da mesma 30 avós que não moravam com os netos, antes nem após a separação/divórcio dos pais. O instrumento utilizado foi um questionário contendo itens que atendiam aos objetivos da pesquisa, bem como os dados sóciodemográficos. Os resultados indicaram uma preferência, por parte dos avós, pelas atividades do tipo emocional, notando-se um aumento, em geral, após a separação/divórcio, nas seguintes atividades: dar conselhos, transmitir informações sobre a família, telefonar e uma diminuição na atividade visitar.

Palavras-chave: Avós-netos, Relacionamento intergeracional, Separação/divórcio.
\end{abstract}

\begin{abstract}
The grandparents role: Support offered to the grandchildren before and after situations of parent's separation/divorce

The present research aimed to discover the types of support offered by the grandparents to grandchildren, before and after the parents' separation/divorce, as well as the possible changes in the forms of support. Two types of support were analyzed: the emotional and the instrumental, considering the influence of the following variables: geographical distance, custody, maternal or paternal link, age, marital status and grandparents' job situation. The subjects were 30 grandparents who didn't live with their grandchildren, before or after the parent's separation/divorce, were selected. The instrument used was a questionnaire with items which met the objectives of the research. The social demographic factors were also considered. Results indicated a preference for activities of the emotional type, with a general increase, after the separation/divorce, in activities such as: giving advice, transmitting information concerning the family, and telephoning. There was a decrease in the visiting activities.
\end{abstract}

Key words: Grandparents-grandchildren, intergerational relationship, divorce/separation.

A S taxas concernentes ao processo de separação/divórcio entre casais vêm aumentando consideravel mente nas mais variadas culturas e camadas sociais. Conforme dados apresentados por Waldemar (1996) o número de divórcio nos países ocidentais atinge cerca de 30 a $50 \%$ dos casamentos. No que diz respeito ao Brasil, foram encerrados, em primeira instância, 36. 251 processos de divórcio, no ano de 1985, e 99. 887, no ano de 1995, o que demonstra que houve um aumento de $175,5 \%$ neste período. Quanto ao número de processos de separa- 
ção judicial, foram encerrados 76. 296, em 1985, e 88. 118, em 1995, denotando um aumento de 15,5\% (Instituto Brasileiro de Geografia e Estatística [IBGE], 1985, 1995).

Conforme demonstram os dados acima, as dissoluções de casamentos, cada vez mais, estão fazendo parte do cotidiano das famílias. Apesar do alto índice de separação/divórcio, as repercussões emocionais desse processo são um assunto ainda relativamente novo, mesmo na área da terapia familiar (Waldemar, 1996).

Dentre as teorias psicológicas que abordam o indivíduo no seu contexto familiar e que podem explicar a importância dos avós para a família separada/divorciada destacam-se: a Teoria do Ciclo Vital da Família, que tem Betty Carter e Mônica McGoldrick como principais defensoras, e a Teoria Geral dos Sistemas (TSG), cujo precursor foi Ludwig von Bertalanffy. De acordo com a última, a mudança em uma parte do sistema afeta a unidade inteira. Por isto, outros membros da família, além das díades imediatas pais-filhos, também podem ser influenciados pelo divórcio.

Após os cônjuges e seus filhos, os avós são considerados os parentes que mais tendem a sofrer as conseqüências desfavoráveis desse rompimento, uma vez que se verifica, normalmente, seu envolvimento neste momento delicado que seu filho ou filha está passando (Jaskowski \& Dellasega, 1993).

Da mesma forma, a Teoria do Ciclo Vital da Família afirma que o divórcio apresenta-se como o maior rompimento do ciclo de vida da família, acarretando um aumento nas tarefas desenvolvimentais que a mesma está vivenciando. Neste processo, há uma interrupção do ciclo de vida familiar normal e a tomada de uma nova direção, o que implica uma necessidade de reformulação de regras de funcionamento da família e o desenvolvimento de novas capacidades adaptativas nos papéis que cada membro desenvolve no contexto dos novos subsistemas familiares que se formam (Carter \& McGoldrick, 1995).

Não raro, o casal e seus filhos encontram-se despreparados para o impacto físico e emocional deste rompimento. Sendo assim, cada fase seguinte do ciclo de vida fica afetada pelo divórcio. Todavia, se a família for capaz de negociar a crise e as transições que necessitam ser vivenciadas a fim de reestabilizar-se, ela, então, terá estabelecido um sistema mais fluido que irá permitir a continuidade do processo de desenvolvimento familiar normal (Peck $\&$ Manocherian, 1995).

Convém aludir ao fato de que, embora a separação/divórcio dos cônjuges esteja, em sua maioria, associada a conseqüências negativas e devastadoras para os membros envolvidos, muitas famílias são beneficiadas com esta transição, sobretudo aquelas em que a violência física e/ou verbal eram condições preponderantes. Dito de outra forma, a separação/divórcio pode caracterizar-se, em determinados ca- sos, como uma possibilidade para resgatar ou promover a saúde do sistema familiar. Autores como Costa, Penso e Féres-Carneiro (1992), Kaslow e Schwartz (1995), Souza (2000) chamam a atenção para os aspectos positivos da separação/divórcio.

Cabe salientar ainda que, embora os avós também sejam influenciados pela separação/divórcio de um(a) filho(a), é mais provável que eles estejam numa fase estável nas suas vidas, sendo possível que possam prestar assistência emocional ou expressiva e instrumental a seus filhos, ex-genros/ noras e netos, desempenhando, então, um papel mais atuante (Gladstone, 1988; Jonhson, 1988). No entanto, esta contribuição está relacionada a diversos fatores como: distância geográfica, custódia parental, situação empregatícia, idade, sexo e estado civil dos avós, entre outros (Gladstone, 1987; Jaskowski \& Dellasega, 1993).

Também é mister considerar que, não obstante a ênfase esteja voltada, na maioria das vezes, para os benefícios que os avós podem trazer, sobretudo no que tange ao desenvolvimento de seus netos, a influência é recíproca. Pode-se dizer, portanto, que a relação entre essas duas gerações é mutuamente importante. Neste sentido, Maldonado e Goldin (1995) afirmam que os netos exercem fundamental importância na vida dos avós e que o contato entre avós e netos pode ser essencial para as pessoas que estão envelhecendo. Segundo Wilson e DeShane (1982) a importância dos netos para os avós é eloqüente e negar o acesso dos avós a seus netos pode ser nocivo para ambos.

Na verdade, embora a importância da mutualidade dessa relação seja hoje reconhecida, sabe-se que foi principalmente durante a década de 80 que o interesse nos estudos sobre os avós cresceu consideravelmente. Dentre os fatores que são apontados como contribuindo para tal situação destacam-se: a maior expectativa de vida do ser humano na sociedade atual, que, por sua vez, leva as pessoas a vivenciarem, por mais tempo, o papel de avós e até o de bisavós; o incremento de outras organizações familiares (como as famílias monoparentais, destacando-se aí as famílias divorciadas/separadas e as famílias recasadas); a crescente participação da mulher no mercado de trabalho, e, ainda, a influência que assume esta figura, especialmente, no que concerne à gravidez na adolescência, nos casos de excepcionalidade da criança, uso de drogas ou morte dos pais (Dias \& Silva, 1999).

$\mathrm{Na}$ realidade brasileira havia uma escassez de estudos realizados sobre os avós, mas nota-se um crescimento no interesse sobre o tema: Dias, 1983; Barros, 1987; Dias, 1994; Oliveira, 1993; Fraiman, 1996; Atalla, 1996; Araújo, Silva e Dias, 1998; Silva e Dias, 1998; Dias e Silva, 1999 e Silva e Dias, 1999. No entanto, quando se trata de avós que vivenciaram a separação/divórcio de um(a) filho(a), a escassez é maior. 
Com base no que foi até então abordado, surgiu o interesse por este estudo, cujo objetivo foi averiguar o tipo de apoio oferecido pelos avós aos netos, antes e após situações de separação/divórcio dos pais, bem como a existência de mudanças no mesmo. Além disto, procurou-se verificar, acerca do apoio oferecido pelos avós aos netos, a influência das seguintes variáveis: distância geográfica; custódia parental; vinculação materna ou paterna; idade dos avós; estado civil dos avós; situação empregatícia dos avós.

\section{Método}

\section{Amostra}

Os sujeitos foram 30 avós que não moravam com seus netos, antes nem após a separação/divórcio dos pais. Adotou-se o critério da idade dos netos ser até 12 anos baseado em Gladstone (1988) pois, segundo este autor, as crianças com doze anos de idade ou menos são, especialmente, mais atingidas pelos efeitos negativos da separação/divórcio dos pais, como também é provável que os netos compreendidos nesta faixa etária precisam mais do apoio dos avós.

Todos os avós residiam na cidade de João Pessoa, estando seus(suas) filhos(as) separados/divorciados(as) há, pelo menos, dois anos. Este critério do tempo de separação/ divórcio foi adotado com base na afirmação de Kaslow e Schwartz (1995) de que, para que haja uma adaptação à separação, o tempo necessário é, em média, de dois a quatro anos. Além disso, a intenção de pré-determinar um tempo mínimo de separação/divórcio foi uma forma de evitar que fizessem parte do estudo avós cujos(as) filhos(as) não estivessem verdadeiramente separados/divorciados(as) mas, apenas, passando por uma crise conjugal.

\section{Instrumento}

Foi elaborado um questionário cuja estrutura contemplou questões fechadas (dicotômicas e de múltipla resposta) e questões abertas. O mesmo foi dividido em três partes: a primeira ficou composta de 6 itens que diziam respeito ao apoio oferecido pelos avós aos netos, bem como às variáveis que poderiam influenciar o mesmo, no período antecedente à separação/divórcio da geração do meio. A segunda, por sua vez, foi composta de 6 itens que correspondiam aos mesmos aspectos, porém no período conseqüente à dissolução do casamento dos filhos. Finalmente, a terceira parte, constituiu-se de questões referentes aos dados sócio-demográficos acerca das três gerações (avós, filhos e netos).

\section{Procedimentos para a coleta de dados}

Os respondentes foram localizados em suas próprias residências sendo que um(a) avô (avó) sempre indicou, pelo menos, um(a) outro(a). A coleta de dados foi realizada durante um período de três meses e o questionário levou cerca de duas a três horas para ser respondido. Optou-se por ler o instrumento para todos os avós indistintamente, bem como anotar as respostas dadas pelos mesmos.

Salienta-se que todos os avós foram orientados a responder às questões do instrumento, pensando na família de um(a) de seus(as) filhos(as) separados(as)/ divorciados(as). Caso os avós tivessem mais de um(a) filho(a) nesta condição, deviam responder ao instrumento pensando no(a) que se separou/divorciou primeiro, devido ao maior impacto da primeira separação. Da mesma forma, se os avós tivessem mais de um(a) neto(a) que fosse filho(a) desse(a) filho(a) separado(a)/divorciado(a) com doze anos de idade ou menos, deviam escolher apenas um(a) para falar a respeito e depois indicar o motivo que os levou à escolha do(a) mesmo(a).

\section{Resultados}

O SPSS (Statistical Package for Social Sciences) foi utilizado na construção de um banco de dados para análise das informações contidas no instrumento da coleta dos dados. As variáveis estudadas foram mensuradas nos níveis das escalas: nominal, ordinal e intervalar.

Verificou-se, inicialmente, com o uso do SPSS, a consistência das informações, ou seja, foi feita a correção da codificação das variáveis no banco de dados, e, em seguida, procedeu-se à análise estatística através da construção de tabelas de freqüências e cruzamentos das variáveis pertinentes, para o levantamento do perfil dos avós, pais e netos, objetos de estudo.

Na seqüência da análise estatística e, de acordo com os objetivos propostos, utilizou-se o Teste Não-paramétrico de Wilcoxon, em nível de significância de $1 \%$ ou $5 \%$, para verificar a existência de mudanças no apoio fornecido pelos avós aos netos, após situações de separação/divórcio dos pais, sob a influência das seguintes variáveis: distância geográfica, custódia parental; tipo de vinculação familiar; idade dos avós; estado civil e situação empregatícia. Também foi observada, através do Teste Binomial (a um nível de significância de 5\%), a existência ou não de diferenças significativas no total de apoio emocional ou instrumental fornecido pelos avós aos netos, antes e após a separação/divórcio dos pais.

A Tabela 1 apresenta os dois tipos de apoio e as respectivas atividades que os avós realizam com os netos, antes e após a separação/divórcio dos pais.

Os resultados da Tabela 1 mostram que, dentre as várias atividades que compreendem o apoio emocional, houve um aumento significativo, após a separação/di- 


\section{Tabela 1}

\section{Descrição do tipo de suporte oferecido pelos avós aos netos antes e após a}

\begin{tabular}{|c|c|c|c|c|c|c|}
\hline \multirow[t]{2}{*}{ Variável } & \multirow[t]{2}{*}{ Atividades } & \multicolumn{2}{|c|}{ Antes } & \multicolumn{2}{|c|}{ Depois } & \multirow{2}{*}{$\begin{array}{c}\text { Teste de } \\
\text { Wilxocon } \\
\text { (Signif. p) }\end{array}$} \\
\hline & & $\mathrm{n}$ & $\%$ & $\mathrm{n}$ & $\%$ & \\
\hline \multirow{13}{*}{$\begin{array}{l}\text { Suporte } \\
\text { Emocional }\end{array}$} & Dá carinho & 29 & 96,7 & 28 & 93,3 & n.s. \\
\hline & Visita & 23 & 76,7 & 14 & 46,7 & $0,0164 *$ \\
\hline & Dá presentes & 23 & 76,7 & 25 & 83,3 & n.s. \\
\hline & Passeia & 10 & 33,3 & 11 & 36,7 & n.s. \\
\hline & Dá conselhos & 9 & 30,0 & 21 & 70,0 & $0,0047 * *$ \\
\hline & Transmite informações sobre a família & 7 & 23,3 & 15 & 50,0 & $0,0249 *$ \\
\hline & Telefona & 5 & 16,7 & 14 & 46,7 & $0,0077 * *$ \\
\hline & Desenvolve atividades religiosas & 5 & 16,7 & 8 & 26,7 & n.s. \\
\hline & Transmite outras informações & 5 & 16,7 & 8 & 26,7 & n.s. \\
\hline & Viaja & 2 & 6,7 & 5 & 16,7 & n.s. \\
\hline & Castiga & 2 & 6,7 & 6 & 20,0 & \\
\hline & Envia correspondências & - & - & 1 & 3,3 & n.s. \\
\hline & Não mantêm nenhuma atividade & - & - & 1 & 3,3 & n.s. \\
\hline \multirow{9}{*}{$\begin{array}{l}\text { Suporte } \\
\text { Instrumental }\end{array}$} & Permite que fique em casa & 25 & 83,3 & 23 & 76,7 & n.s. \\
\hline & Ajuda a cuidar na doença & 14 & 46,7 & 16 & 53,3 & n.s. \\
\hline & Ajuda financeiramente & 12 & 40,0 & 9 & 30,0 & n.s. \\
\hline & Prepara as refeições & 9 & 30,0 & 11 & 36,7 & n.s. \\
\hline & Leva ao médico & 7 & 23,3 & 8 & 26,7 & n.s. \\
\hline & Leva à escola & 6 & 20,0 & 4 & 13,3 & n.s. \\
\hline & Alimenta & 6 & 20,0 & 6 & 20,0 & n.s. \\
\hline & Ajuda nas tarefas escolares & 4 & 13,3 & 7 & 23,3 & n.s. \\
\hline & Não mantêm nenhuma atividade & 3 & 0,10 & 7 & 23,3 & n.s. \\
\hline
\end{tabular}

$\left({ }^{*}\right)=$ valor: $\mathrm{p}<0,05$ significativo a $5 \% \mathrm{e}\left({ }^{* *}\right)=$ valor: $\mathrm{p}<0,01$ significativo a $1 \%$

Tabela 2.

Teste binomial para o total de suporte emocional e instrumental oferecido pelos avós aos netos, antes e após a separação/divórcio dos pais

\begin{tabular}{lccccc}
\hline Tipo de Suporte & & Situação & & $\begin{array}{c}\text { Teste } \\
\text { Binomial } \\
\text { (Signif. p) }\end{array}$ & Total \\
\cline { 2 - 5 } & Antes & Depois & & \\
Emocional & 120 & 157 & $0,0305 *$ & 277 \\
Instrumental & 86 & 91 & n.s. & 177 \\
Total & 206 & 248 & & 454 \\
\hline
\end{tabular}

$(*)=$ valor: $\mathrm{p}<0,05$ significativo a $5 \%$

vórcio da geração do meio, nas seguintes atividades: dar conselhos $(p<0,01)$, transmitir informações sobre a família $(p<0,05)$ e telefonar $(p<0,01)$. Note-se que, no caso das visitas, houve uma significativa diminuição $(p<0,05)$.

Quanto às atividades que fazem parte do apoio instrumental, embora algumas delas tenham aumentado tais como, ajudar a cuidar dos netos na doença, preparar suas refeições, levá-los ao médico e ajudar nas suas tarefas escolares, essas mudanças não foram significativas.

A Tabela 2 demonstra as diferenças significativas entre o total de apoio emocional e instrumental fornecido pelos avós aos netos, após a separação/divórcio dos pais, através do Teste Binomial. 
Tabela 3.

Comparação entre as atividades do suporte emocional que os avós oferecem aos netos antes e após a separação/divórcio dos pais, de acordo com a distância geográfica $(n=30$

\begin{tabular}{|c|c|c|c|c|c|c|c|c|}
\hline \multirow[t]{2}{*}{ Variável } & \multirow[t]{2}{*}{ Atividades } & & \multicolumn{2}{|c|}{$\begin{aligned} \leq & 30 \text { minutos } \\
& (\mathrm{n}=20)\end{aligned}$} & \multirow{2}{*}{$\begin{array}{c}\text { Teste de } \\
\text { Wilxocon } \\
\text { (Signif. } \\
\text { p) }\end{array}$} & \multicolumn{2}{|c|}{$\begin{array}{c}>30 \text { minutos } \\
\quad \underline{(\mathrm{n}=10)}\end{array}$} & \multirow{2}{*}{$\begin{array}{l}\text { Teste de } \\
\text { Wilxocon } \\
\text { (Signif. } \\
\text { p) }\end{array}$} \\
\hline & & & $\mathrm{n}$ & $\%$ & & $\mathrm{n}$ & & \\
\hline & \multirow{2}{*}{ Visita } & Antes & 15 & 50,0 & & 8 & 26,7 & \\
\hline & & Depois & 8 & 26,7 & $0,0180 *$ & 6 & 20,0 & n.s. \\
\hline & \multirow{2}{*}{$\begin{array}{l}\text { Dá } \\
\text { conselhos }\end{array}$} & Antes & 6 & 20,0 & & 3 & 10,0 & \\
\hline & & Depois & 16 & 53,3 & $\begin{array}{l}0,0051 \\
* *\end{array}$ & 5 & 16,7 & n.s. \\
\hline & \multirow{2}{*}{$\begin{array}{l}\text { Transmite } \\
\text { informações } \\
\text { familiares }\end{array}$} & Antes & 4 & 13,3 & & 3 & 10,0 & \\
\hline & & Depois & 11 & 36,7 & $0,0180 *$ & 4 & 13,3 & n.s. \\
\hline & \multirow{2}{*}{ Telefona } & Antes & 4 & 13,3 & & 1 & 3,3 & \\
\hline & & Depois & 11 & 36,7 & $0,0180 *$ & 3 & 10,0 & n.s. \\
\hline
\end{tabular}

Os resultados do Teste Binomial indicam que há um aumento significativo no total de apoio emocional antes e após a separação/divórcio dos pais, enquanto que no apoio instrumental, isto não se verifica.

A Tabela 3 mostra as atividades correspondentes ao apoio emocional que os avós fornecem aos netos, antes e após a separação/divórcio dos pais, tendo como parâmetro a distância geográfica.

De acordo com os resultados da tabela 3, os avós que moravam há trinta minutos ou menos de carro de seus netos, antes e após a separação/divórcio dos pais, aumentaram significativamente as atividades de: dar conselhos $(p<0,01)$, transmitir informações sobre a família ( $p$ $<0,05)$ e telefonar $(p<0,05)$. Note-se que, também neste caso, as visitas diminuíram significativamente $(p<0,05)$. Com relação aos avós que moravam mais distante que trinta minutos de carro de seus netos, não se observou qualquer mudança significativa em nenhuma das atividades.

Na Tabela 4, são apresentados os resultados referentes ao apoio emocional que os avós fornecem aos netos, antes e após a separação/divórcio dos pais, conforme a custódia parental.

No que diz respeito à influência da custódia parental, observa-se que quando os filhos têm a custódia das crianças houve diferenças significativas em dar conselhos $(\mathrm{p}<0,05)$ e transmitir informações sobre a família ( $\mathrm{p}<$ $0,05)$. Por outro lado, quando é o(a) ex-genro/nora que detém a custódia das crianças, a única atividade que apresentou um aumento significativo foi telefonar para os netos $(\mathrm{p}<0,05)$. Estes avós também diminuíram significativamente suas visitas à geração mais nova $(\mathrm{p}<0,05)$.

A Tabela 5 apresenta as atividades que fazem parte do apoio emocional em relação à vinculação materna ou paterna.

Em relação à vinculação paterna ou materna, verificase que os avós paternos aumentaram significativamente $a$ atividade de telefonar para seus netos $(p<0,05)$. Os avós maternos, por sua vez, aumentaram significativamente a atividade de dar conselhos $(\mathrm{p}<0,05)$. Uma outra constatação foi que as visitas realizadas pelos avós paternos diminuíram de maneira significativa $(\mathrm{p}<0,05)$, enquanto que as realizadas pelos avós maternos, muito embora tenham diminuído, esta mudança não foi estatisticamente significativa.

A Tabela 6, apresentada a seguir, diz respeito à comparação entre as atividades do apoio emocional que os avós fornecem aos netos, antes e após a separação/divórcio dos pais, de acordo com a idade dos avós.

Em relação à idade dos avós, observa-se que aqueles com 65 anos ou menos aumentaram significativamente as atividades de dar conselhos e telefonar para os netos ( $p$ 
Tabela 4 .

Comparação entre as atividades do suporte emocional que os avós

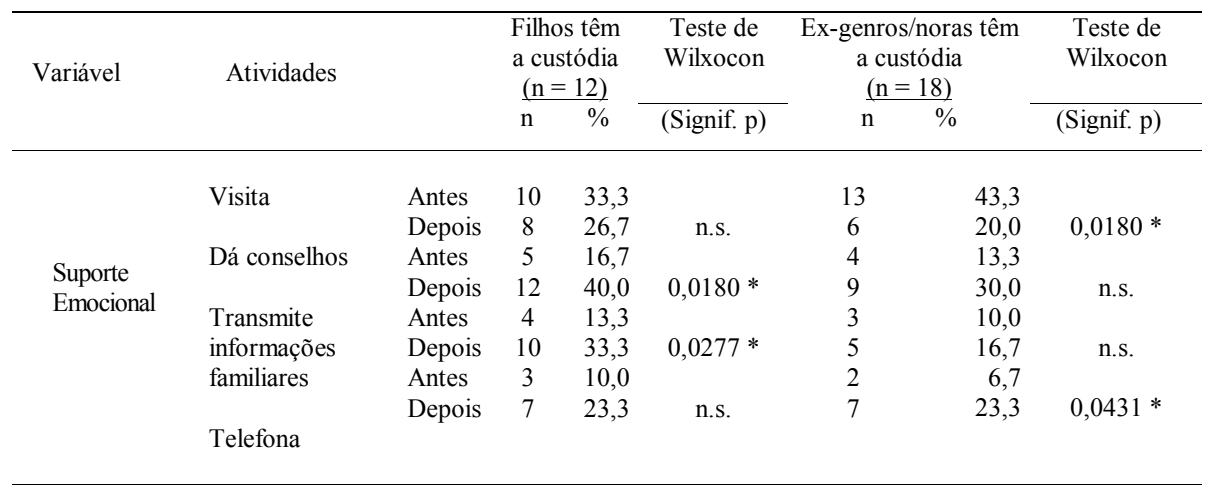

$(*)=$ valor: $\mathrm{p}<0,05$ significativo a $5 \%$ e $\left({ }^{* *}\right)=$ valor: $\mathrm{p}<0,01$ significativo a $1 \%$

$<0,05)$. Os avós com mais de 65 anos, por sua vez, diminuíram significativamente suas visitas aos netos $(p<0,05)$.

Na Tabela 7 apresentam-se os resultados da comparação entre as atividades correspondentes ao apoio emocional que os avós fornecem aos netos, antes e após a separação/divórcio dos pais, conforme o estado civil dos avós.

No que concerne ao estado civil dos avós, verificase que aqueles que eram casados apresentaram um aumento estatisticamente significativo nas atividades de dar conselhos $(p<0,01)$; transmitir informações sobre a família $(\mathrm{p}<0,05)$ e telefonar $(\mathrm{p}<0,05)$. Quanto às visitas realizadas por esses avós, elas diminuíram significativamente $(\mathrm{p}<0,05)$. No que diz respeito aos avós que não estavam casados, não houve diferenças significativas em nenhuma das atividades assinaladas por eles.
Finalmente, a Tabela 8 apresenta a comparação entre as atividades do apoio emocional que os avós fornecem aos netos, antes e após a separação/divórcio dos pais, tendo como parâmetro a situação empregatícia dos avós.

No que diz respeito à situação empregatícia dos avós, os resultados da Tabela 8 evidenciam que aqueles que estavam exercendo alguma atividade profissional, após a separação dos filhos, deram maior ênfase à atividade de telefonar para os netos $(\mathrm{p}<0,05)$. Os avós que não estavam exercendo uma atividade profissional, por sua vez, deram maior ênfase às atividades de dar conselho $(\mathrm{p}<$ $0,01)$ e transmitir informações sobre a família $(\mathrm{p}<0,05)$. Percebe-se ainda que, dentre as atividades fornecidas por esses últimos avós, as visitas foram as únicas que apresentaram uma diminuição significativa $(\mathrm{p}<0,05)$.

\section{Tabela 5.}

Comparação entre as atividades do suporte emocional que os avós

\begin{tabular}{|c|c|c|c|c|c|c|c|c|}
\hline \multirow{2}{*}{ Variável } & \multirow{2}{*}{ Atividades } & & \multicolumn{2}{|c|}{$\begin{array}{l}\text { Avós paternos } \\
(\mathrm{n}=18)\end{array}$} & \multirow{2}{*}{$\begin{array}{c}\text { Teste de } \\
\text { Wilxocon } \\
\text { (Signif. p) }\end{array}$} & \multicolumn{2}{|c|}{$\begin{array}{l}\text { Avós maternos } \\
\quad(\mathrm{n}=12)\end{array}$} & \multirow{2}{*}{$\begin{array}{c}\text { Teste de } \\
\text { Wilxocon } \\
\text { (Signif. p) }\end{array}$} \\
\hline & & & $\mathrm{n}$ & $\%$ & & $\mathrm{n}$ & $\%$ & \\
\hline \multirow{6}{*}{$\begin{array}{l}\text { porte } \\
\text { nocional }\end{array}$} & Visita & Antes & 13 & 43,3 & & 10 & 33,3 & \\
\hline & & Depois & 6 & 20,0 & $0,0180 *$ & 8 & 26,7 & n.s. \\
\hline & Dá conselhos & Antes & 4 & 13,3 & & 5 & 16,7 & \\
\hline & & Depois & 10 & 33,3 & n.s. & 11 & 36,7 & $0,0277 *$ \\
\hline & Telefona & Antes & 2 & 6,7 & & 3 & 10,0 & \\
\hline & & Depois & 7 & 23,3 & $0,0431 *$ & 7 & 23,3 & n.s. \\
\hline
\end{tabular}

$(*)=$ valor: $\mathrm{p}<0,05$ significativo a $5 \%$ e $(* *)=$ valor: $\mathrm{p}<0,01$ significativo a $1 \%$ 
Tabela 6.

Comparação entre as atividades do suporte emocional que os avós oferecem aos netos antes e após a separação/divórcio dos pais, de acordo com a idade dos avós $(n=30)$

\begin{tabular}{|c|c|c|c|c|c|c|c|c|}
\hline \multirow{2}{*}{ Variável } & \multirow{2}{*}{ Atividades } & & \multicolumn{2}{|c|}{$\begin{array}{c}\leq 65 \text { anos } \\
(\mathrm{n}=16)\end{array}$} & \multirow{2}{*}{$\begin{array}{c}\text { Teste de } \\
\text { Wilxocon } \\
\text { (Signif. p) }\end{array}$} & \multicolumn{2}{|c|}{$\begin{array}{c}>65 \text { anos } \\
(\mathrm{n}=14)\end{array}$} & \multirow{2}{*}{$\begin{array}{c}\text { Teste de } \\
\text { Wilxocon } \\
\text { (Signif. p) }\end{array}$} \\
\hline & & & $\mathrm{n}$ & $\%$ & & $\mathrm{n}$ & $\%$ & \\
\hline \multirow{6}{*}{$\begin{array}{l}\text { Suporte } \\
\text { Emocional }\end{array}$} & Visita & Antes & 12 & 40,0 & & 11 & 36,7 & \\
\hline & & Depois & 10 & 33,3 & n.s. & 4 & 13,3 & $0,0180 *$ \\
\hline & Dá conselhos & Antes & 3 & 10,0 & & 6 & 20,0 & \\
\hline & & Depois & 10 & 36,7 & $0,0117 *$ & 10 & 33,3 & n.s. \\
\hline & Telefona & Antes & 4 & 13,3 & & 1 & 3,3 & \\
\hline & & Depois & 10 & 33,3 & 0,0277 * & 4 & 13,3 & n.s. \\
\hline
\end{tabular}

$(*)=$ valor: $\mathrm{p}<0,05$ significativo a $5 \%$ e $(* *)=$ valor: $\mathrm{p}<0,01$ significativo a $1 \%$

\section{Discussão}

Esta discussão dos resultados considerará tanto os dados apresentados nas tabelas como alguns trechos obtidos ao longo das entrevistas realizadas com os avós.

De acordo com Gladstone (1989) os avós, após um processo de separação/divórcio, prestam assistência não só aos seus filhos e netos, mas também aos genros/noras. Duas razões podem explicar este comportamento: 1) eles se sentem emocionalmente perto dessas pessoas; 2) esta assistência lhes permitirá livre acesso aos netos.

Segundo a Tabela 1, as atividades mais valorizadas por estes avós foram as que compõem o apoio emocional: dar conselhos, transmitir informações sobre a família e telefonar.

A visita foi uma atividade que diminuiu significativamente após a transição familiar representada pela separação/divórcio. Tal resultado é incompatível com os resultados da pesquisa realizada por Gladstone (1988), na qual o autor verificou que houve aumento nas visitas dos avós aos netos, mesmo sob a influência de fatores estruturais como distância geográfica e custódia dos filhos. A diminuição significativa na atividade de visitas do presente estudo, provavelmente, está relacionada ao fato de que, no momento das entrevistas, era deixado claro para os

Tabela 7.

Comparação entre as atividades do suporte emocional que os avós oferecem aos netos antes e após a separação/divórcio dos pais, de acordo com o estado civil dos avós $(n=30)$

\begin{tabular}{|c|c|c|c|c|c|c|c|c|}
\hline \multirow[t]{3}{*}{ Variável } & \multirow[t]{3}{*}{ Atividades } & & \multirow{2}{*}{\multicolumn{2}{|c|}{$\begin{array}{l}\text { Casados } \\
(\mathrm{n}=25) \\
\end{array}$}} & \multirow[t]{2}{*}{$\begin{array}{c}\text { Teste de } \\
\text { Wilxocon }\end{array}$} & \multicolumn{2}{|c|}{$\begin{array}{l}\text { Não-casados } \\
\quad(\mathrm{n}=5)\end{array}$} & \multirow{2}{*}{$\begin{array}{c}\text { Teste de } \\
\text { Wilxoco } \\
\text { n }\end{array}$} \\
\hline & & & & & & $\mathrm{n}$ & $\%$ & \\
\hline & & & & & (Signif. p) & & & $\begin{array}{l}\text { (Signif. } \\
\text { p) }\end{array}$ \\
\hline \multirow{9}{*}{$\begin{array}{l}\text { Suporte } \\
\text { Emocional }\end{array}$} & \multirow[t]{2}{*}{ Visita } & Antes & 20 & 66,7 & & 3 & 10,0 & \\
\hline & & Depois & 12 & 40,0 & $0,0249 *$ & 2 & 6,7 & n.s \\
\hline & \multirow{2}{*}{ Dá conselhos } & Antes & 6 & 20,0 & & 3 & 10,0 & \\
\hline & & Depois & 17 & 56,7 & $0,0071 *$ & 4 & 13,3 & n.s. \\
\hline & \multirow{4}{*}{$\begin{array}{l}\text { Transmite } \\
\text { informações } \\
\text { familiares }\end{array}$} & Antes & 5 & 16,7 & & 2 & 6,7 & \\
\hline & & Depois & 12 & 40,0 & $0,0382 *$ & 3 & 10,0 & n.s. \\
\hline & & Antes & 5 & 16,7 & & - & 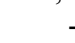 & \\
\hline & & Depois & 13 & 43,3 & $0,0117 *$ & 1 & 3,3 & n.s. \\
\hline & Telefona & & & & & & & \\
\hline
\end{tabular}

$(*)=$ valor: $\mathrm{p}<0,05$ significativo a $5 \%$ e $(* *)=$ valor: $\mathrm{p}<0,01$ significativo a $1 \%$ 
Tabela 8.

Comparação entre as atividades do suporte emocional que os avós oferecem aos netos antes e após a separação/divórcio dos pais, de acordo com a situação empregatícia dos avós $(n=30)$

\begin{tabular}{|c|c|c|c|c|c|c|c|c|}
\hline \multirow{2}{*}{ Variável } & \multirow{2}{*}{ Atividades } & & \multicolumn{2}{|c|}{$\begin{array}{c}\text { Ativos } \\
(\mathrm{n}=16)\end{array}$} & \multirow[t]{2}{*}{$\begin{array}{c}\text { Teste de } \\
\text { Wilxocon }\end{array}$} & \multicolumn{2}{|c|}{$\begin{array}{l}\text { Inativos } \\
(\mathrm{n}=14) \\
\end{array}$} & \multirow[t]{2}{*}{$\begin{array}{c}\text { Teste de } \\
\text { Wilxocon }\end{array}$} \\
\hline & & & $\mathrm{n}$ & $\%$ & & $\mathrm{n}$ & $\%$ & \\
\hline & & & & & (Signif. p) & & & (Signif. p) \\
\hline \multirow{8}{*}{$\begin{array}{l}\text { Suporte } \\
\text { Emocional }\end{array}$} & Visita & Antes & 6 & 20,0 & & 17 & 56,7 & \\
\hline & & Depois & 5 & 16,7 & n.s. & 9 & 30,0 & $0,0249 *$ \\
\hline & Dá conselhos & Antes & 3 & 10,0 & & 6 & 20,0 & \\
\hline & & Depois & 4 & 13,3 & n.s. & 17 & 56,7 & $0,0071 *$ \\
\hline & Transmite informações & Antes & 3 & 10,0 & & 4 & 13,3 & \\
\hline & familiares & Depois & 3 & 10,0 & n.s. & 12 & 40,0 & $0,0117 *$ \\
\hline & & Antes & - & - & & 5 & 16,7 & \\
\hline & Telefona & Depois & 5 & 16,7 & $0,0431 *$ & 9 & 30,0 & n.s. \\
\hline
\end{tabular}

$(*)=$ valor: $\mathrm{p}<0,05$ significativo a $5 \%$ e $(* *)=$ valor: $\mathrm{p}<0,01$ significativo a $1 \%$

avós que os mesmos deveriam se referir às atividades apenas quando eles próprios tomassem a iniciativa de realizá-las. Sendo assim, como são os filhos, principalmente as filhas, que fazem o movimento de buscar o apoio dos avós, estes não precisam se deslocar para visitá-los, daí a diminuição na atividade de visitas por parte deles.

A partir do Teste Binomial realizado (ver Tabela 2) verificaram-se diferenças significativas entre o total de apoio emocional, antes e após a separação/divórcio, o que não aconteceu com o apoio instrumental. Embora ambos os apoios tenham aumentado após a transição familiar, o apoio emocional foi mais valorizado que o instrumental, o que corrobora pesquisa anterior (Gladstone, 1987).

Dias e Silva (1999), numa revisão da literatura sobre os avós, constataram que a maioria deles prefere ter seu relacionamento com os netos baseado em trocas expressivas, voluntárias e envolvido num clima de amizade. Um avô expressou sua preferência pelas atividades que são baseadas nos aspectos voluntários da relação dizendo:

Eu adoro contar estórias pra minha neta. Quando eu conto estórias pra minha neta, ela começa a sorrir, acha graça. Uma vez eu contei pra ela que eu matava gato e cachorro novo e ela ficou horrorizada. Quando ela foi embora morar em outra cidade com sua mãe, deixou uma gatinha grávida aqui e ligou de lá pedindo a avó dela para cuidar dos gatinhos novos por causa do vovô. Quer dizer, ela lembrou-se não é? Então é importante o que eu falo pra minha neta.

Quando os apoios fornecidos pelos avós foram cruzados com a distância geográfica (ver Tabela 3), notou-se que os avós que moravam há trinta minutos ou menos de carro de seus netos deram-lhes mais apoio do que os que moravam há mais de trinta minutos. As atividades mais valorizadas também foram as de dar conselhos, telefonar e transmitir informações sobre a família. Neste caso, ficou evidenciado que a distância geográfica é uma variável que dificulta a relação avós-netos, pois quando os avós moravam mais perto de seus netos, ambos desenvolviam uma quantidade maior de atividades, sobretudo de cunho emocional. Vários pesquisadores enfocaram a importância da variável distância geográfica na freqüente interação entre avós e netos, encontrando resultados semelhantes (Gladstone, 1987; 1988; Silva \& Dias, 1998; Silva \& Dias, 1999). Para Gladstone (1987) embora a proximidade geográfica não garanta um maior contato entre as duas gerações, propicia mais chances para que isto aconteça.

No que concerne à custódia parental (ver Tabela 4), os dados revelaram que, quando os fillhos detêm a custódia das crianças, os avós fornecem mais conselhos e transmitem informações familiares para seus netos, após a separação/divórcio dos pais. Quando são os ex-genros/ noras que detêm a custódia, há um aumento significativo na atividade de telefonar e uma diminuição nas visitas. É possível que os avós cujos filhos detêm a custódia das crianças tenham mais oportunidade de estar com seus netos e, assim, oferecerem mais conselhos e informações sobre a família. Por outro lado, os avós cujos ex-genros/ noras detêm a custódia dos filhos podem ter suas relações com os netos dificultadas, como pode ser observado no depoimento de uma avó: "Eu não gosto da minha ex-nora porque ela não presta, não vale nada. Ela esconde o meu neto pra eu não ver." 
Segundo Gladstone (1987) os principais motivos que podem dificultar o relacionamento avós-netos após a separação dos pais são os conflitos não resolvidos e as dificuldades de renegociar os relacionamentos.

Outros estudiosos que analisaram a influência da custódia parental verificaram que entre as avós cujos próprios filhos tinham a custódia das crianças, a maioria (81\%) estava "muito satisfeita" com o seu relacionamento com os netos. Por outro lado, entre as avós cujos genros/noras detinham a custódia, somente $38,5 \%$ estavam "muito satisfeita" (Jaskowski \& Dellasega, 1993). Também Gladstone (1987) e Kruk e Hall (1995) verificaram que pais de filhos que detêm a custódia têm maior contato com os netos e que o relacionamento entre a avó e a mãe tende a se intensificar após uma situação de separação/divórcio na família.

Relacionando o tipo de custódia parental (ver Tabela 4) com a outra variável estudada - a vinculação materna ou paterna - (Ver Tabela 5), pudemos observar que elas exercem uma influência mútua. Ou seja, a mãe que é, geralmente, quem detém a custódia dos filhos, passa a buscar o apoio de sua família de origem e, conseqüentemente, aproxima-a de seus filhos, o que não ocorre tanto com o pai (Ahrons \& Bowman, 1982; Johnson, 1988; Hetherington, 1989; Kruk \& Hall, 1995). Em decorrência disto, o contato e o envolvimento dos avós paternos com seus netos pode ficar prejudicado.

Na Tabela 5, verificou-se que os avós paternos valorizaram muito mais a atividade de telefonar para os netos. Os avós maternos, por sua vez, deram maior ênfase à atividade de dar conselhos. As visitas realizadas pelos avós paternos diminuíram significativamente após a separação/divórcio dos filhos, ao passo que as realizadas pelos avós maternos, embora tenham diminuído, tal mudança não foi significativa.

Como já foi mencionado, na maioria dos casos, é a mãe quem fica com a custódia das crianças após a separação e, possivelmente, isto facilita mais o contato de seus filhos com os pais delas. Em conseqüência disto, os avós maternos podem dar mais conselhos aos seus netos quando vão à casa de suas filhas ou quando eles (filhas e netos) vão às suas casas. Por outro lado, os avós paternos, provavelmente, tendo mais dificuldade ao acesso de seus netos, podem ter, como opção de comunicação, o telefone.

A importância da vinculação materna ou paterna na mediação da relação entre avós e netos tem sido pesquisada e os resultados encontrados não diferem dos que foram obtidos no presente estudo. Por exemplo, Johnson (1988), numa pesquisa longitudinal realizada ao longo de 40 meses com 50 famílias que haviam experienciado uma separação/divórcio, detectou que as avós paternas tinham menos contato pessoal e providenciavam menos apoio social e emocional a seus netos que as avós maternas. Creasey (1993) observou que a qualidade do relacionamento entre netos e avós paternos, após a separação/divórcio, foi menos satisfatória entre estes do que entre netos e avós maternos.

No que se refere à idade dos avós (ver Tabela 6), foi visto que os avós com 65 anos ou menos, desempenham um número maior de atividade com os netos, sobretudo as de aconselhar e telefonar para eles. Entre os avós com mais de 65 anos, o único resultado estatisticamente significativo foi que eles diminuíram suas visitas à geração mais nova. De fato, é bem possível que os avós mais novos sintam-se mais dispostos para visitar e/ou desenvolver atividades, seja de cunho emocional ou instrumental, com seus netos. Além disso, é provável que estes avós tenham menos problemas de saúde, o que pode lhes favorecer maior possibilidade de interação. Uma avó declarou:

Eu não posso ir visitar o meu neto nem brincar muito com ele quando ele vem aqui com minha filha, porque eu já tô velha e tenho muitos problemas nos ossos. Eu tenho artrite e artrose e isso dói muito.

A idade dos avós, portanto, é uma variável importante na interação entre as gerações, como fora descrito por Johnson (1988). Esta autora encontrou que as avós mais jovens tinham contatos mais freqüentes com seus filhos, ex-genros e netos, após o processo de separação/divórcio, que as avós mais velhas. Além disso, a idade das avós também apareceu como determinante importante na assistência que elas prestavam aos netos, verificando-se que as mulheres mais novas forneciam significativamente mais ajuda que as mais velhas.

Gladstone (1988), porém, afirmou que, embora a idade dos avós possa ter influência no contato entre avós e netos, a idade dos netos pode ser mais importante na alteração da relação que a idade dos avós. O autor justificou que a geração mais velha pode se conformar com o tipo de relação e freqüência de contato que mantém com os netos. Em contrapartida, os netos podem desejar mudar sua relação, à medida que ficam mais velhos e entram na adolescência. Na verdade, é bem provável que, ao ficarem mais velhos, os netos tenham mais iniciativa e autonomia para visitar seus avós enquanto os netos pequenos geralmente ficam à mercê dos pais, no que concerne à visita aos avós. Esta visão é também compartilhada por Kalish e Visher (1982).

O estado civil dos avós foi outra variável analisada como mediadora na relação avós-netos (ver Tabela 7). Os resultados encontrados mostraram que os avós que estavam casados aumentaram significativamente as atividades de dar conselhos, transmitir informações sobre a família e telefonar, muito embora tenha sido observada uma diminuição significativa em suas visitas. Isto não 
aconteceu com os avós que não estavam casados. Estes resultados são compatíveis com aqueles encontrados no estudo realizado por Gladstone (1988), no qual se constatou que as avós que estavam casadas, no momento da separação dos filhos, apresentaram um aumento estatisticamente significativo no apoio prestado aos netos. Para o autor, as avós que não estão casadas podem se contentar com a ausência do marido formando diferentes tipos de relacionamentos que podem não excluir, mas também não enfatizar, seu relacionamento com os netos.

É realmente possível que, após ficarem viúvos ou se separarem/divorciarem, alguns avós queiram canalizar suas energias para atividades que não estejam diretamente vinculadas a aspectos de responsabilidades recuperando, assim, o tempo perdido. Estar envolvidos com os netos, embora tenha sido relatado por muitos avós como uma atividade prazerosa, não exclui a aura de responsabilidade que isto envolve. Uma avó divorciada comentou: "Eu não crio a minha neta, mas falo para que a mãe assuma a filha, que cuide direito dela, porque minha concepção de família é assim: a criança tem que ficar com os pais.”

Em relação à influência da situação empregatícia dos avós no relacionamento com seus netos (ver Tabela 8) observou-se que, entre os avós que estavam trabalhando após o descasamento dos filhos, a única atividade que apresentou diferença significativa foi telefonar para os netos. Os avós que não estavam trabalhando, por sua vez, aumentaram significativamente as atividades de dar conselho e transmitir informações sobre a família, embora suas visitas aos netos tenham diminuído significativamente.

Esses resultados são corroborados pelo estudo de Gladstone (1988). Malgrado o autor não ter encontrado qualquer associação estatisticamente significativa entre a situação empregatícia dos avós e mudanças na relação com os netos - posto que a natureza do grupo estudado era homogênea, ou seja, a maioria dos avós não trabalhava ele admitiu que esta variável pode influenciar na relação entre a geração mais nova e a mais velha, após a separação/ divórcio dos pais.

Acredita-se que os avós participantes do presente estudo que trabalhavam fora podem ter dado maior ênfase à atividade de telefonar por ser o telefone um veículo prático de comunicação com os netos. Como não têm muito tempo livre para dedicarem-se a eles, é provável que os avós optem por telefonar para os mesmos visando manter o vínculo afetivo.

É interessante notar que apenas uma minoria de avós não presta qualquer tipo de apoio instrumental, nem antes, nem após a separação/divórcio dos pais (conforme Tabela 1), o que vem comprovar o que fora salientado por Hader (1965), Neugarten e Weinstein (1964),
Robertson (1977), de um não envolvimento no papel dos avós por parte de alguns.

\section{Considerações finais}

Conclui-se que todos os membros da família (avós, filhos e netos) sofrem alterações em seu desenvolvimento, com a ocorrência de uma separação/divórcio. Assim sendo, torna-se imprescindível a existência de abertura e flexibilidade entre eles para redefinirem seus papéis e suas relações familiares, buscando-se sempre o equilíbrio do sistema vigente. Como, muitas vezes, o próprio período de tensão que estão passando não possibilita que isto aconteça, acredita-se que a implementação de trabalhos preventivos (grupos de pais e de avós oriundos de famílias separadas/divorciadas, cursos para avós) possam ser uma alternativa no sentido de preservar ou promover a saúde dos membros e fortalecer a relação existente.

Convém ressaltar que, malgrado um processo de separação/divórcio possa constituir uma situação desestabilizadora para o sistema familiar, a maneira como isso pode repercutir em cada membro irá depender de uma série de fatores. Outrossim, os resultados mostraram que os avós podem desempenhar um relevante papel para a família, fornecendo assistência tangível (apoio instrumental) e intangível (apoio emocional). No entanto, a extensão desta assistência dependerá de variáveis como: distância geográfica, custódia parental, vinculação materna ou paterna, idade, estado civil e situação empregatícia dos avós.

Reconhece-se uma limitação no presente estudo ao considerar a amostra independente do sexo dos sujeitos, quando se sabe que esta também é uma variável importante. Entretanto, devido à pouca quantidade de respondentes do sexo masculino sua análise não foi possível, o que poderia ter enriquecido ainda mais o trabalho. No entanto, esta e outras variáveis podem ser objeto de futuras pesquisas.

\section{Referências}

Ahrons, C., \& Bowman, M. (1982). Changes in family relationships following divorce of adult child: grandmother's perceptions. Journal of Divorce, 5, 49-68.

Araújo, M., Silva, D., \& Dias, C. M. S. B. (1998). A figura dos avós nos âmbitos psicossocial e familiar. Mente Social, 4(2), 23-33.

Atalla, M. (1996). Netos, o olhar das avós: vivência de avós que cuidam de seus netos. Dissertação de Mestrado não-publicada, Universidade de São Paulo, São Paulo.

Barros, M. L. (1987). Autoridade e afeto: avós, filhos e netos na família brasileira. Rio de Janeiro: Jorge Zahar.

Carter, B., \& McGoldrick, M. (1995). As mudanças no ciclo de vida familiar: uma estrutura para a terapia familiar $\left(2^{\mathrm{a}} \mathrm{ed}\right.$.). Porto Alegre: Artes Médicas (Texto original publicado em 1989).

Costa, L. F. , Penso, M. A., \& Féres-Carneiro, T. (1992). Reorganizações familiares: as possibilidades de saúde a partir da separação conjugal. Psicologia Teoria e Pesquisa, 6(Suplemento), 495-503. 
Creasey, G. (1993). The association between divorce and late adolescent grandchildren's relations with grandparents. Journal of Youth and Adolescence, 22(5), 513-529.

Dias, C. M. S. B. (1983). Interação familiar: a influência dos avós sobre a família nuclear. Estudo de caso. Dissertação de mestrado nãopublicada, Universidade de Brasília, Brasília.

Dias, C. M. S. B. (1994). A importância dos avós no contexto familiar. Psicologia: Teoria e Pesquisa, 10, 31-40.

Dias, C. M. S. B., \& Silva, D. V. (1999). Os avós: uma revisão da literatura nas três últimas décadas. In T. Féres-Carneiro (Org.), Casal e familia, entre a tradição e a transformação (pp. 118-149). Rio de Janeiro: Nau.

Fraiman, A. (1996). Para ser um bom avô. São Paulo: Gente.

Gladstone, J. (1987). Factors associated with changes in visiting between grandmothers and grandchildren following an adult child's marriage breakdown. Canadian Journal on Aging, 6, 117-127.

Gladstone, J. (1988). Perceived changes in grandmother-grandchild relations following a child's separation or divorce. The Gerontologist, 28, 66-72.

Gladstone, J. (1989). Grandmother-grandchild contact: the mediating influence of the middle generation following marriage breakdown and remarriage. Canadian Journal on Aging, 8, 355-365.

Hader, M. (1965). The importance of grandparents in family life. Family Process, 4, 228-238.

Hetherington, E. (1989). Coping with family transitions: winners, losers and survivors. Child Development, 60, 1-14.

Instituto Brasileiro de Geografia e Estatística [IBGE] (1985). Estatísticas do Registro Civil. Rio de Janeiro: Autor.

Instituto Brasileiro de Geografia e Estatística [IBGE] (1995). Estatísticas do Registro Civil. Rio de Janeiro: Autor.

Jaskowski, S., \& Dellasega, C. (1993). Effects of divorce on the grandparentgrandchild relationship. Issues in Comprehensive Pediatric Nursing, $16,125-133$.
Johnson, C. (1988). Active and latent functions of grandparenting during the divorce process. The Gerontologist, 28, 185-191.

Kalish, R., \& Visher, E. (1982). Grandparents of divorce and remarriage. Journal of Divorce, 5, 127-140.

Kaslow, F., \& Schwartz, L. (1995). As dinâmicas do divórcio: uma perspectiva de ciclo vital. Campinas: Psy. (Texto original publicado em 1987).

Kruk, E., \& Hall, B. (1995). The disengagement of paternal grandparents subsequent to divorce. Journal of Divorce \& Remarriage, 23, 131-147.

Maldonado, M., \& Goldin, A. (1995). Maiores de 40: guia de viagem para a vida ( $3^{\mathrm{a}}$ ed.). São Paulo: Saraiva.

Neugarten, B., \& Weinstein, K. (1964). The changing american grandparent. Journal of Marriage and the Family, May, 199-204.

Oliveira, P. (1993). Vidas compartilhadas: o universo cultural nas relações entre avós e netos. Tese de doutorado não-publicada, Universidade de São Paulo, São Paulo.

Peck, J., \& Manocherian, J. (1995). O divórcio nas mudanças do ciclo de vida familiar. In B. Carter \& M. McGoldrick (Orgs.), As mudanças no ciclo de vida familiar: uma estrutura para a terapia familiar $\left(2^{\mathrm{a}} \mathrm{ed}\right.$., pp. 291-320). Porto Alegre: Artes Médicas.

Robertson, J. (1977). Grandmotherhood: A study of role conceptions. Journal of Marriage and the Family, February, 165-174.

Silva, D. V., \& Dias, C. M. S. B. (1998). Relacionamento avós-netos na percepção de adolescentes. Anais do III Congresso Brasileiro de Terapia Familiar (pp. 184-188), Rio de Janeiro: ABRATEF.

Silva, N. P., \& Dias, C. M. S. B. (1999). Avós e avôs: percepção do papel. Revista Symposium - Nova Fase, 3(Número Especial), 51- 67.

Souza, R. M. (2000). Depois que papai e mamãe se separaram: um relato dos filhos. Psicologia Teoria e Pesquisa, 16, 203-211.

Waldemar, J. O. C. (1996). Divórcios e recasamentos, enfrentando o desconhecido. In L. C. Prado (Org.), Famílias e Terapeutas, construindo caminhos (p. 173-188). Porto Alegre: Artes Médicas.

Wilson, K., \& DeShane, M. (1982). The legal rights of grandparents: a preliminary discussion. The Gerontologist, 22, 67-71.

\section{Notas}

1 Consiste das seguintes atividades: telefonar, enviar correspondências, visistar, passear, dar presentes, dar conselhos, dar carinho, viajar, desenvolver atividades religiosas, transmitir informações sobre a família, castigar, transmitir outros tipos de informações.

2 Compreende as atividades de: levar à escola, ajudar nas tarefas escolares, levar ao médico, preparar as refeições, alimentar, permitir que os netos fiquem em sua casa na ausência dos pais, cuidar dos netos quando eles estão doentes, ajudar financeiramente.

Mayeve Rochane Gerônimo Leite Araújo, mestre em Desenvolvimento Humano pela Universidade Federal da Paraíba, PB, é professora do Departamento de Psicologia da Universidade Estadual da Paraíba, Campina Grande, PB.

Cristina Maria de Souza Brito Dias, doutora em Psicologia Social pela Universidade de Brasília, é professora e Coordenadora do Mestrado em Psicologia Clínica da Universidade Católica de Pernambuco, PE.

Endereço para correspondência: Rua Conselheiro Portela, 130A/ apt. 201, Espinheiro, 52020-030, Recife, PE. E-mail: [MRGLA] mayeve@braslink.com.br; [CMSB] propesp@unicap.br. 